Revista do Departamento de Geografia
Universidade de São Paulo
www.revistas.usp.br/rdg

\title{
MAPEAMENTO DO CULTIVO DE CAFÉ NO SUL DE MINAS GERAIS UTILIZANDO IMAGENS LANDSAT-5 TM E VARIÁVEIS TOPOGRÁFICAS
}

\author{
MAPPING COFFEE CROPS IN THE SOUTH OF MINAS GERAIS \\ USING LANDSAT-5 TM IMAGERY AND TOPOGRAPHIC VARIABLES
}

\author{
Daniel Fernando Costa do Prado \\ Universidade Federal de Lavras \\ danfernando010@gmail.com \\ Ericson Hideki Hayakawa \\ Universidade Estadual do Oeste do Paraná \\ Fernando Shinji Kawakubo \\ Universidade de São Paulo
}

Recebido (Received): 31/08/2015 Aceito (Accepted): 12/12/2015
DOI: http://dx.doi.org/10.11606/rdg.v31i0.103040

Resumo: Esta pesquisa tem como objetivo mapear os cultivos de café na região de Muzambinho, Cabo Verde e Monte Belo, Sul de Minas Gerais, utilizando imagens Landsat-5 Thematic Mapper e Modelos Digitais do Terreno. A área de estudo localiza-se em uma tradicional região produtora de café, onde o cultivo é praticado, na maioria das vezes, em áreas de relevo fortemente ondulado. Para a realização da pesquisa, incialmente aplicou-se um modelo de iluminação para a correção do efeito topográfico, com o objetivo de reduzir as variações espectrais causadas pelo relevo e assim melhorar o resultado da classificação. Em seguida, as imagens foram segmentadas e classificadas utilizando um algoritmo supervisionado por regiões. Duas classes de café que expressam diferentes condições fenológicas foram consideradas: Café Formação e Café Produção. Os resultados mostram que a correção topográfica melhorou o desempenho da segmentação criando segmentos mais contínuos e representativos das formas dos cultivos. Além disto, um aumento no desempenho da classificação foi observado ao comparar os resultados obtidos no presente estudo com uma classificação convencional pela máxima verossimilhança.

Palavras-Chave: uso da terra; correção topográfica; segmentação; classificação por região, sul de Minas Gerais, Landsat TM.
Abstract: This research aims to map coffee crops in the region of Muzambinho, Cabo Verde and Monte Belo, Southern Minas Gerais by using Landsat-5 Thematic Mapper imagery and Digital Terrain Model. The study area is located in a traditional coffee-producing province where most of the coffee-growing lands are set on mountainous relief. To perform this study, an illumination model was used to correct the topographic effect and thus, reduce the spectral variations caused by the relief displacement. After this, the imagery were segmented and classified using a supervised classifier by region. We considered for this analysis two classes of coffee expressing different phenological condition: Coffee Formation and Coffee Production. The results showed that the topographic correction improved the segmentation performance creating more continuous and representative segments of the coffee fields. Furthermore, an increase of the classification performance was found by comparing the results obtained in this study with a conventional per-pixel maximum likelihood classification.

Keywords: land-use; topographic correction; segmentation; region classification; Southern Minas Gerais, Landsat TM. 


\section{INTRODUÇÃO}

A produção de café no Brasil exerce importante função econômica e social. Segundo dados da Companhia Nacional de Abastecimento (CONAB, 2010), o Brasil é responsável por 32\% da exportação mundial de café, sendo o sul do estado de Minas Gerais, a principal área produtora. Também conhecida como região cafeicultora de montanha, o cultivo de café no sul de Minas Gerais é bastante diversificado (variando de tamanho e na forma de produção), com destaque para o cultivo em pequenas propriedades.

As estimativas oficiais brasileiras das safras de café são realizadas pelo Instituto Brasileiro de Geografia e Estatística (IBGE) e pela CONAB, que utilizam como base para o cálculo, informações declaradas de produção por parte de agricultores e técnicos agrícolas. Tal metodologia possui a desvantagem de adotar critérios subjetivos na fase de amostragem, o que pode enviesar a estimativa de produção.

Em função da demanda crescente de café no mercado nacional e do aumento da receita cambial gerada pela exportação, o aprimoramento de metodologias que fazem uso de critérios objetivos destinados à previsão de safra é fundamental para evitar especulações do mercado (MOREIRA et al., 2004) e apoiar medidas que visem o planejamento agrícola e as tomadas de decisões. O sensoriamento remoto consiste numa das principais tecnologias de apoio aos estudos agrícolas, fornecendo informações valiosas a respeito da distribuição areal, das condições biofísicas e da dinâmica dos cultivares (MOREIRA et al., 2007; RAMIREZ e ZULLO JÚNIOR, 2010; BERNARDES et al., 2012).

Tradicionalmente, o mapeamento do cultivo de café por meio de sensoriamento remoto apoia-se nos elementos de reconhecimento da fotointerpretação (CERON e DINIZ, 1966). Os mapeamentos gerados por meio da fotointerpretação, seja a partir de fotografias aéreas ou imagens de satélite, são bastantes eficientes devido à experiência que muitos especialistas possuem no reconhecimento destes alvos. Todavia, tal metodologia é bastante demorada, o que acaba encarecendo o projeto e inviabilizando o monitoramento das mudanças de uso da terra.

Em razão destas limitações, os métodos computacionais de classificação digital exercem papel importante no levantamento das áreas cultivadas. O desenvolvimento de metodologias de classificação digital de imagens tem permitido ao longo dos anos o constante aprimoramento dos levantamentos de uso da terra e cobertura vegetal. Apesar destes constantes avanços, o mapeamento da cultura de café por meio de classificação digital ainda não é uma tarefa trivial de ser executada. Isto se deve especialmente à grande diversidade espectral do cultivo, que é resultante de uma série de fatores, como por exemplo, variações nos tamanhos e formas de plantio, diferenças de idade, de manejo e estágio fenológico etc. (TARDIN et al., 1992; EPIPHANIO et al., 1994; MOREIRA et al., 2004; VIEIRA et al., 2007; MOREIRA et al., 2010).

Além da diversidade espectral que caracteriza o cultivo de café, os erros presentes na classificação digital também são influenciados pelo efeito topográfico (MOREIRA et al., 2015) e pelas limitações dos algoritmos comumente empregados na análise (CORDERO-SANCHO; SADER, 2007). Para a correção da influência do relevo no comportamento espectral dos alvos, técnicas de razões de bandas e modelos de iluminação têm sido utilizados (EKSTRAND, 1996; ALLEN, 2000; RIAÑO et al., 2003). A desvantagem da utilização de razões de bandas é que apesar de minimizar as variações de brilho na imagem, a técnica não é capaz de eliminar completamente a dependência da disposição do relevo.

Um dos classificadores mais utilizados no mapeamento do uso da terra e da cobertura vegetal é o da Máxima Verossimilhança (Maxver). Neste classificador, amostras de treinamento representativas das classes de interesse (normalmente mais de uma centena) são previamente selecionadas. Em seguida, o algoritmo calcula a probabilidade de cada pixel da imagem pertencer a uma das classes amostradas com base na ponderação das distâncias das médias (CRÓSTA, 1992). A desvantagem da utilização do Maxver é que o algoritmo assume que o padrão das classes presentes na imagem segue um modelo de distribuição normal (JENSEN, 2005), o que na realidade, muitas 
vezes não acontece, devido à variabilidade interna das classes. Além disto, tal classificador também não considera o comportamento espectral dos pixels vizinhos na tomada de decisão.

Em razão das dificuldades existentes no mapeamento da cultura do café em áreas de relevo montanhoso, o presente estudo tem como objetivo apresentar uma metodologia de mapeamento que faz uso de correção topográfica e classificação por regiões com o objetivo de aprimorar os atuais métodos de estimativa.

\section{ÁREA DE ESTUDO}

A área de estudo compreende parte dos municípios de Muzambinho, Cabo Verde e Monte Belo, porção à sudoeste da represa de Furnas. Inserida no planalto atlântico, a área de estudo se caracteriza predominantemente pela presença de rochas cristalinas cortadas por intrusivas básicas e alcalinas mesozóicas e terciárias e pelas coberturas das bacias sedimentares (LIMA et al., 2010). A altitude varia de $780 \mathrm{~m}-1260 \mathrm{~m}$, sendo que as áreas de maiores amplitudes topográficas e de declividades encontram-se nas áreas compreendidas pelos limites municipais de Muzambinho e Cabo Verde. As vertentes seguem predominantemente as orientações Leste (E), Sul (S) e Oeste (W). A Figura 1 ilustra a localização da área de estudo (A) e os mapas hipsométrico (B), clinográfico (C) e de orientação das vertentes (D).

As principais atividades econômicas da região são a pecuária e o cultivo de café. A ocupação na região foi intensificada em meados do século XVIII com o enfraquecimento da mineração aurífera no estado. A população que antes se dedicava à mineração, passou a se deslocar para a região sul do estado, onde encontrou condições para se dedicar a agricultura e a pecuária (FILETTO e ALENCAR, 2001). As primeiras plantações de café em larga escala na região, somente ocorreram no final do século XVIII, nos vales do Sapucaí e do rio das Mortes, motivadas pela expansão da lavoura cafeeira do Vale do Paraíba (FILETTO e ALENCAR, 2001). Atualmente, a região é a principal produtora nacional de café, sendo responsável por mais da metade da produção do Estado de Minas Gerais.

Além da pecuária e do café, o cultivo da cana-de-açúcar tem-se expandido ao longo dos últimos anos como consequência dos incentivos governamentais destinados ao setor sucroalcooleiro. Culturas temporárias como milho e feijão, além de plantio de eucalipto também são observados na área de estudo. A vegetação nativa é formada por manchas de florestas semideciduais estacionárias e savana (RADAMBRASIL, 1983). As manchas de florestas estão localizadas principalmente nas áreas de relevo mais íngremes na porção sul (Cabo Verde), e em uma área de reserva particular (RPPN) em Monte Belo (localizada na porção leste).

A Figura 2 ilustra as diferentes formas de uso da terra da área de estudo: A) plantação de cana-de- açúcar no município de Monte Belo; B) cultivo de café em estágio de formação (referido apenas como Café Formação) com idade de aproximadamente 4 anos em Muzambinho; C) café em estágio de produção (referido apenas como Café Produção) plantado ao longo do declive do terreno intercalado por pequenas áreas de eucalipto em Cabo Verde; D) cultivo de café em Cabo Verde em terreno com declividade de $18^{\circ}$; E) diversidade de uso às margens da BR-491, compreendendo parte dos municípios de Muzambinho e Cabo Verde.

\section{MATERIAIS E MÉTODO}

\section{Imagens de satélite}

Utilizou-se neste trabalho as imagens do satélite Landsat-5 Thematic Mapper (TM) bandas TM-3 (vermelho), TM-4 (infravermelho próximo) e TM-5 (infravermelho médio), cuja cena foi tomada no dia 01/05/2009 (órbita 219, ponto 75) correspondente ao período seco. O período seco foi selecionado com o objetivo de obter uma melhor separação espectral entre as áreas de pastagem (que se encontram secas) e as culturas de café e de cana-de-açúcar (esta última no estágio inicial de crescimento). Segundo Moreira et al. (2004; 2010), as imagens adquiridas no período seco, além de 
serem mais eficientes para diferenciar as culturas de café de outras classes de uso da terra, também são as mais adequadas na distinção das áreas de Café Formação e Café Produção.
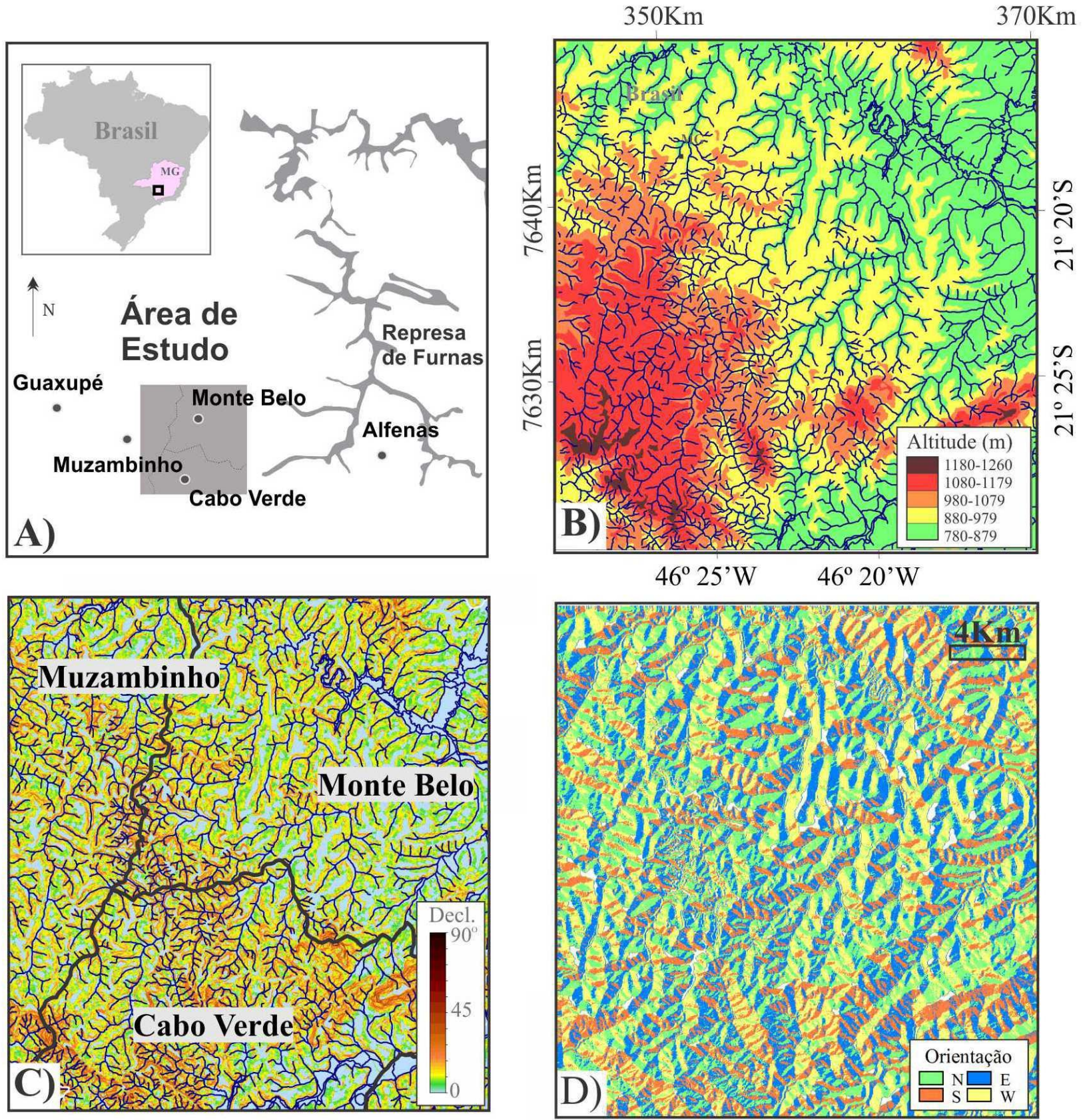

Figura 1: A) Localização da área de estudo no contexto do sul de Minas Gerais. Mapas derivados do Modelo Digital do Terreno: B) hipsometria; C) clinográfico, em graus; D) orientação das vertentes.

\section{Correção geométrica}

Inicialmente as imagens foram corrigidas geometricamente utilizando como referência a carta topográfica na escala 1: 50.000 (folha Monte Belo SF-23-V-D-I-3) obtida em formato digital no sítio do Instituto Brasileiro de Geografia e Estatística. O georreferenciamento da imagem foi feito por meio de pontos de controle identificados na imagem e na base cartográfica. Foram identificados 31 pontos de controle distribuídos ao longo da área de estudo. Após o ajuste dos pontos, utilizando um polinômio de grau 2, o erro de georreferenciamento obtido foi de aproximadamente 1.0 pixel. Em seguida, as imagens foram reamostradas com o interpolador vizinho mais próximo com espaçamento da grade de 30 metros. $\mathrm{O}$ interpolador vizinho mais próximo foi escolhido em razão do algoritmo mencionado preservar no processo de reamostragem o valor do pixel da imagem original (CRÓSTA, 1992). 


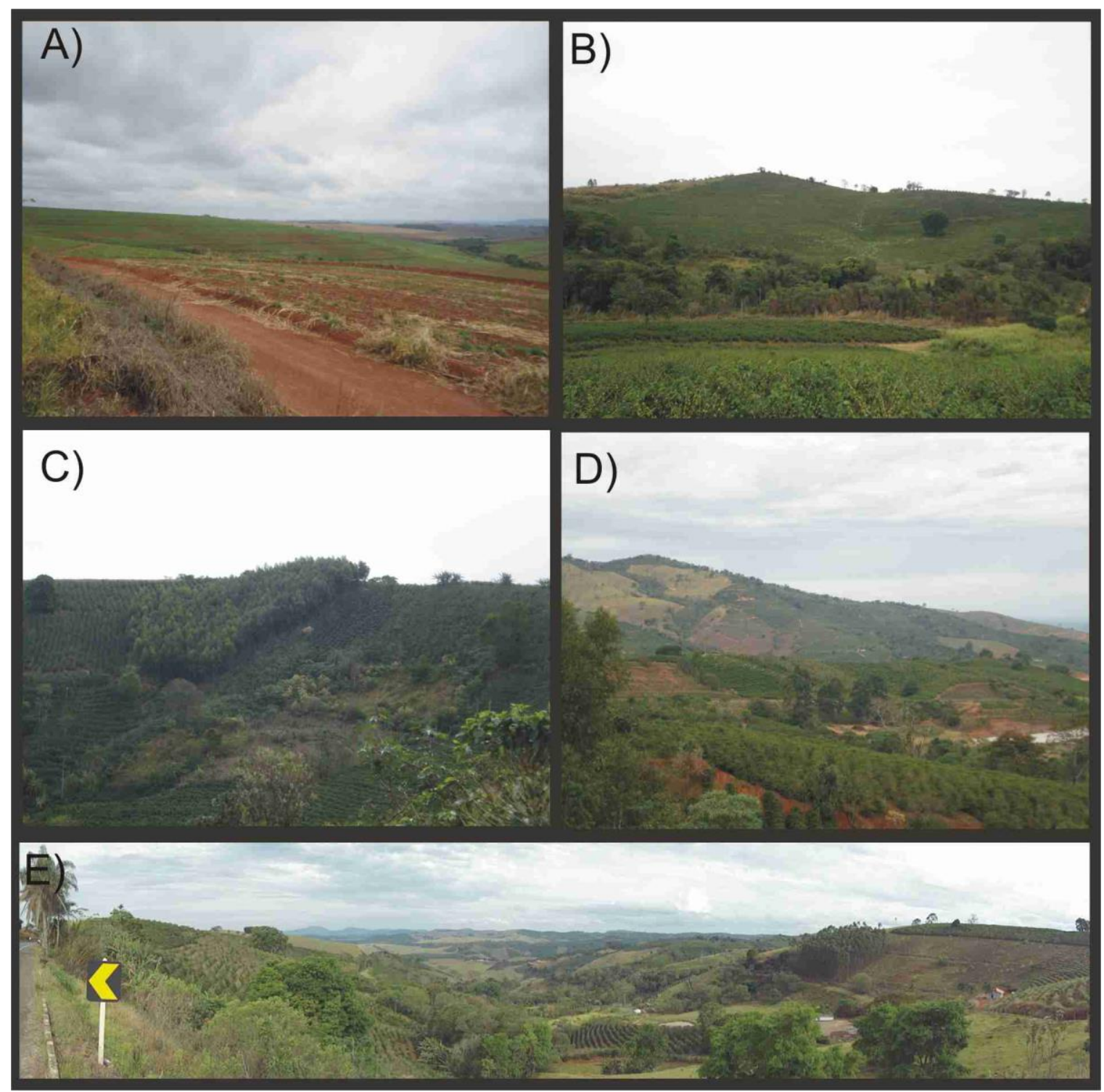

Figura 2: Diversidade de uso da terra da área de estudo. Fotografias tiradas em trabalho de campo realizado em 25 de setembro de 2012.

\section{Modelo digital do terreno e correção topográfica}

O modelo digital do terreno (MDT) foi gerado utilizando as informações de curvas de nível com equidistância de 20 metros extraídas da carta topográfica. Antes de realizar a interpolação das curvas de nível, estas foram editadas para um domínio de valor e submetidas à correção topológica. Para cada curva de nível, foi atribuído o valor da cota altimétrica correspondente. Erros de conexão das curvas de nível também foram corrigidas nesta etapa.

A interpolação das curvas de nível foi realizada utilizando o interpolador Borgefors. Para o cálculo da superfície, inicialmente o algoritmo rasteriza as curvas de nível e em seguida, calcula o valor da superfície com base na distância linear entre duas curvas vizinhas (GORTE e KOOLHOVEN, 1990). Para a geração do MDT, tomou-se o cuidado de adotar os mesmos parâmetros cartográficos e de espaçamento da grade utilizados na correção geométrica das imagens. Este cuidado foi importante para possibilitar a integração das imagens de satélite com os produtos derivados do MDT.

Foram derivados quatro produtos cartográficos a partir do MDT: os mapas hipsométrico, clinográfico e de orientação das vertentes, além do modelo sombreado do relevo. Uma etapa importante da pesquisa foi a correção do efeito topográfico da imagem. Em razão do cultivo de café ser praticado muitas vezes em áreas de relevo fortemente ondulado, a diferença de iluminação resultante da disposição do relevo faz com que as características espectrais do cultivo sejam modificadas. Para realizar esta correção, os parâmetros de aquisição da imagem (ângulo de elevação 
e de azimute) juntamente com o modelo de iluminação derivado do MDT foram utilizados. Optouse em aplicar o método correção do fator cosseno (JENSEN, 2005) que consiste em:

$$
L H=L T \frac{\operatorname{Cos} \theta}{\operatorname{Cosi}}
$$

Onde:

LH é a radiância observada numa superfície horizontal;

LT a radiância observada numa superfície inclinada;

$\theta$ o ângulo zenital solar em graus;

i o ângulo de incidência do sol em relação a normal.

Algumas premissas são adotadas ao utilizar o método do fator cosseno, como por exemplo: a superfície age com um refletor difuso perfeito; a distância entre a terra e o sol é constante; a quantidade de energia solar também é constante. Além disto, não é considerada na modelagem a radiação difusa e a reflexão da radiação advinda do entorno. A principal desvantagem da utilização deste método na correção topográfica de imagens de satélite está relacionada aos problemas de saturação, ondes áreas de maior inclinação do terreno tendem a apresentar valores superestimados de refletância.

Para analisar os resultados da correção topográfica, os valores do fator topográfico foram confrontados com os valores dos pixels das imagens antes e após a correção e também com os valores de declividade e de orientação das vertentes. Para a realização desta análise, a técnica de tabulação cruzada foi empregada.

\section{Segmentação e classificação}

A etapa seguinte consistiu na aplicação da técnica de segmentação com o objetivo de delimitar regiões homogêneas na imagem (HARALICK e SHAPIRO, 1985; ALVES et al., 1996; KAWAKUBO et al., 2009; KAWAKUBO et al., 2013). O critério de homogeneidade adotado em cada região segmentada considerou a homogeneidade espectral observada na composição colorida 543 em RGB (filtros vermelho, verde e azul, respectivamente) e a contextualização do pixel em relação a sua vizinhança. Utilizou-se o método de segmentação por crescimento de regiões implementado no Sistema de Informações Geográficas SPRING (CÂMARA et al., 1996). Nesta segmentação, as regiões são delimitadas com base nos critérios de similaridade dos pixels vizinhos e tamanho mínimo das regiões expresso em número de pixels (BINS et al., 1996).

O algoritmo de segmentação parte de um pixel semente que "cresce" e agrega os pixels vizinhos formando regiões maiores, adotando como critério de crescimento os limiares similaridade e de área. A medida que as regiões se tornam maiores, os valores estatísticos das regiões são constantemente atualizados. O crescimento da região somente é interrompido quando as condições dos limiares não são mais satisfeitas.

No processo de segmentação, foram testados diferentes limiares de similaridade e área. A princípio, foram definidos limiares mais restritivos (valores mais baixos tanto para similaridade quanto para área), partindo do princípio que a área de estudo é formada dominantemente por pequenas propriedades rurais com grande diversidade de uso. Todavia, a adoção de limiares mais restritivos (por exemplo, 10 para similaridade e 12 para área) resultou em um particionamento excessivo da imagem. Ou seja, regiões homogêneas foram particionadas criando segmentos adjacentes com propriedades espectrais similares.

Após a realização de vários testes, optou-se em adotar os limiares 35 para similaridade e 45 para área. Isto significa que apenas lavouras contínuas de café superiores a aproximadamente 4 hectares foram considerados no mapeamento. A avaliação da segmentação foi feita de maneira 
visual, comparando os diferentes resultados da segmentação com relação ao nível de particionamento (falta ou excesso de segmentos criados).

Após a segmentação, as regiões foram agrupadas com um classificador supervisionado que calcula a distância média das regiões baseando-se nas distribuições de probabilidades Bhattacharya (LEÃO et al., 2007). Na etapa de amostragem, foram selecionadas amostras de Café Formação e de Café Produção identificadas na imagem. A classe Café Formação corresponde às áreas recentemente plantadas ou que foram podadas. Já a classe Café Produção corresponde os plantios adultos onde os dosséis das plantas cobrem mais de 50\% do solo (VIEIRA et al., 2007).

Com o objetivo de analisar as confusões de classes no mapeamento, amostras de Mata, Agricultura Temporária e Pastagem, também foram inseridas na classificação.

\section{Análise de exatidão}

Para realizar a validação e análise da classificação, foram coletados 497 pontos distribuídos aleatoriamente na área de estudo. Aproximadamente $20 \%$ destes pontos foram checados em campos, contemplando áreas principalmente próximas às estradas e rodovias. O restante dos pontos de referência foi verificado com auxílio das imagens de alta resolução do Google Earth (MOREIRA et al., 2008). Foi gerada uma matriz de confusão para verificar o nível de concordância e discordância do mapeamento (JENSEN, 2005). A eficácia da metodologia descrita também foi analisada comparando os resultados de exatidão obtida com uma classificação convencional pixel a pixel pela máxima verossimilhança (Maxver).

\section{RESULTADOS E DISCUSSÃO}

Em razão da rugosidade e da disposição do relevo, em vários locais da imagem é possível observar o efeito de sombreamento e de iluminação diferenciada, o que dificulta tanto a identificação quanto o mapeamento do cultivo de café. A Figura 3 ilustra o efeito da iluminação utilizando o modelo sombreado do relevo derivado do MDT. Conforme pode ser observado, as faces mais inclinadas voltadas para os raios solares apresentam maior iluminação, em contraposição às faces opostas, que aparecem escuras.

Com relação aos procedimentos adotados para a correção do efeito topográfico, os resultados obtidos mostraram que o procedimento foi eficiente para reduzir as diferenças de iluminação da imagem. A Figura 4 mostra o efeito da correção topográfica utilizando a composição colorida 543 em RGB do satélite Landsat TM. Conforme pode ser observado, a imagem sem correção topográfica (A) apresenta uma aparência com textura mais rugosa, especialmente nas áreas de relevo mais dissecado, em razão da diferença de iluminação. Já a imagem com correção topográfica (B), apresenta uma aparência mais "achatada", resultante do aumento da radiância nas áreas sombreadas e redução da radiância nos locais de maior iluminação.

O efeito de compensação da iluminação resultante da correção topográfica (MOREIRA et al., 2015) também pode ser observado ao analisar a distribuição dos pixels da banda 4 do TM (infravermelho próximo) juntamente com os valores do fator cosseno (Cos $i$ ). Valores baixos do fator cosseno correspondem às áreas de pouca iluminação, enquanto valores altos, representam áreas fortemente iluminadas. Com base neste princípio, é possível observar na Figura 5 uma dependência bastante pronunciada entre o fator cosseno e a radiância da banda TM4 (A). Ou seja, a medida que os valores do fator cosseno aumentam, observa-se também um aumento nos valores de radiância da banda TM-4. Após a aplicação da correção topográfica (B), observa-se uma redução considerável de brilho nas áreas com fatores de cosseno mais altos e um incremento de radiância nos fatores de cosseno mais baixos. 


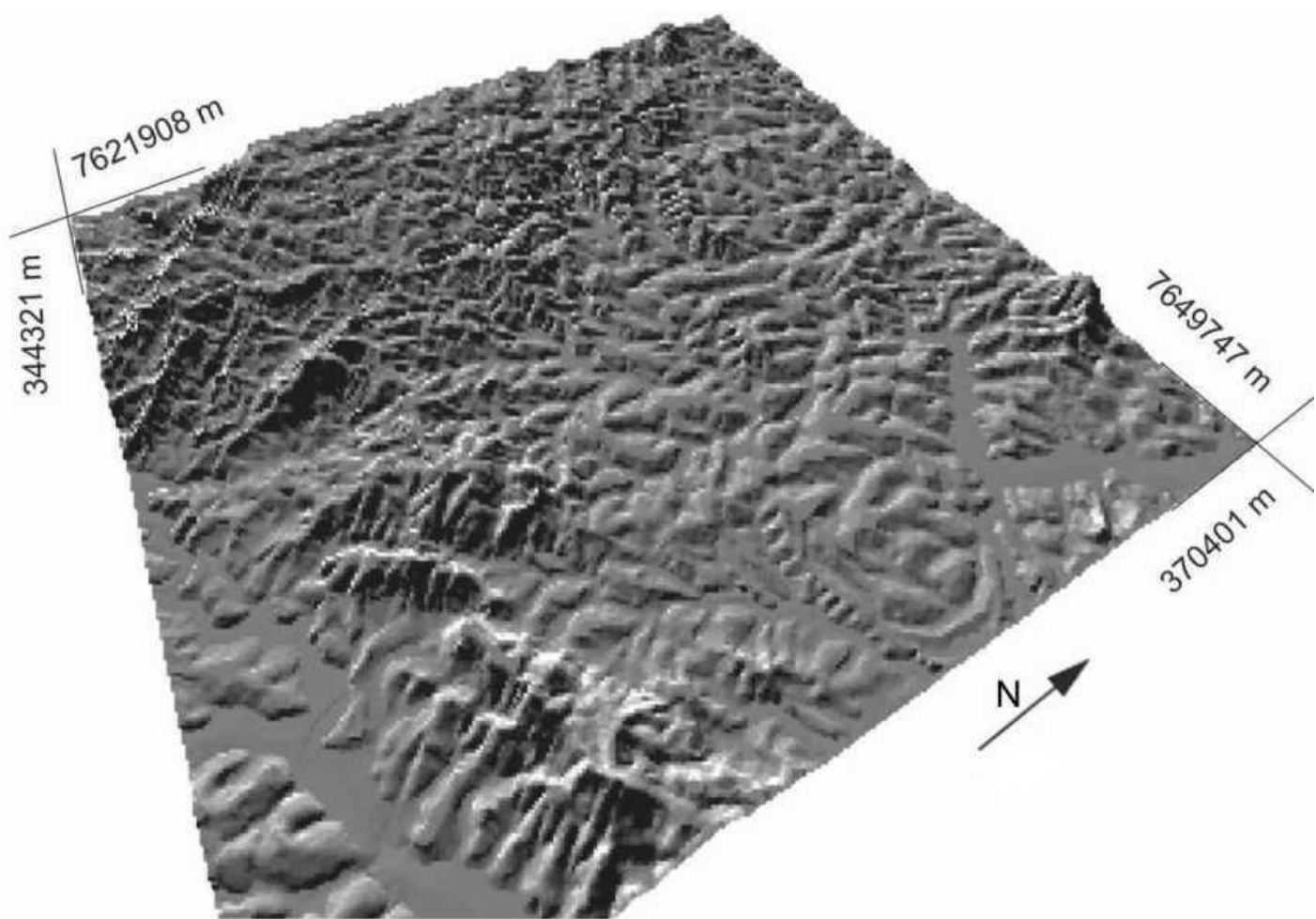

Figura 3: Ilustração tridimensional da área de estudo mostrando o modelo sombreado do relevo derivado do MDT. Parâmetros da visualização do modelo 3D: ângulo vertical (120 graus); rotação horizontal (60 graus); rotação vertical (45 graus); distância do observador (26Km); Exagero vertical (3 vezes).

Apesar da correção topográfica ter melhorado significativamente as diferenças de brilho na imagem, problemas de saturação (aumento excessivo de brilho) também foram observados. Ao analisar de maneira mais detalhada o resultado da correção do efeito topográfico com os produtos derivados do MDT, constatou-se que a saturação ocorreu com maior frequência nas áreas com declividade média de $28^{\circ}$ e vertentes voltadas para Sudoeste. Apesar destes problemas, os resultados da correção topográfica foram interpretados como sendo satisfatórios, pois em áreas planas, os valores de radiância dos cultivos de café foram pouco modificados, e em áreas de maior declive, culturas que antes não podiam ser discriminadas em razão do intenso sombreamento ou iluminação passaram a ser consideradas na análise.

Conforme pode ser observado na Figura 6, onde as áreas em verde correspondem predominantemente ao cultivo de café, a correção topográfica também melhorou o desempenho da segmentação. Em (A), observa-se um forte controle de iluminação causado pela disposição do relevo. Áreas de cultivos de café nas faces iluminadas e sombreadas são particionadas na segmentação. Já em (B), observa-se uma redução na variabilidade espectral do cultivo de café e uma segmentação mais contínua, evidenciando, portanto, uma melhora no processo de segmentação.

No geral, os cultivos de café (Café Formação e Café Produção) foram razoavelmente bem classificados, todavia, confusões principalmente com áreas de mata, pastagem e cultura anuais foram observadas dependendo do estágio fenológico do cultivo.

As áreas de Café Formação são evidenciadas na composição colorida 543 em RGB com coloração verde clara semelhante aos pastos verdes e os cultivos como milho, feijão e cana de açúcar. Quando os cultivos de Café Formação ainda se encontram nos estágios iniciais de desenvolvimento, os cultivos se assemelham as áreas de pastagem e/ou de solo exposto devido a dominância da interação da radiação eletromagnética com os materiais presentes nos espaçamentos dos cultivos. Estudos realizados por Moreira et al. (2010), mostram que em razão deste efeito, a identificação das lavouras de café em imagens TM só é possível em plantio com idade maior ou igual a 2,5 anos. 


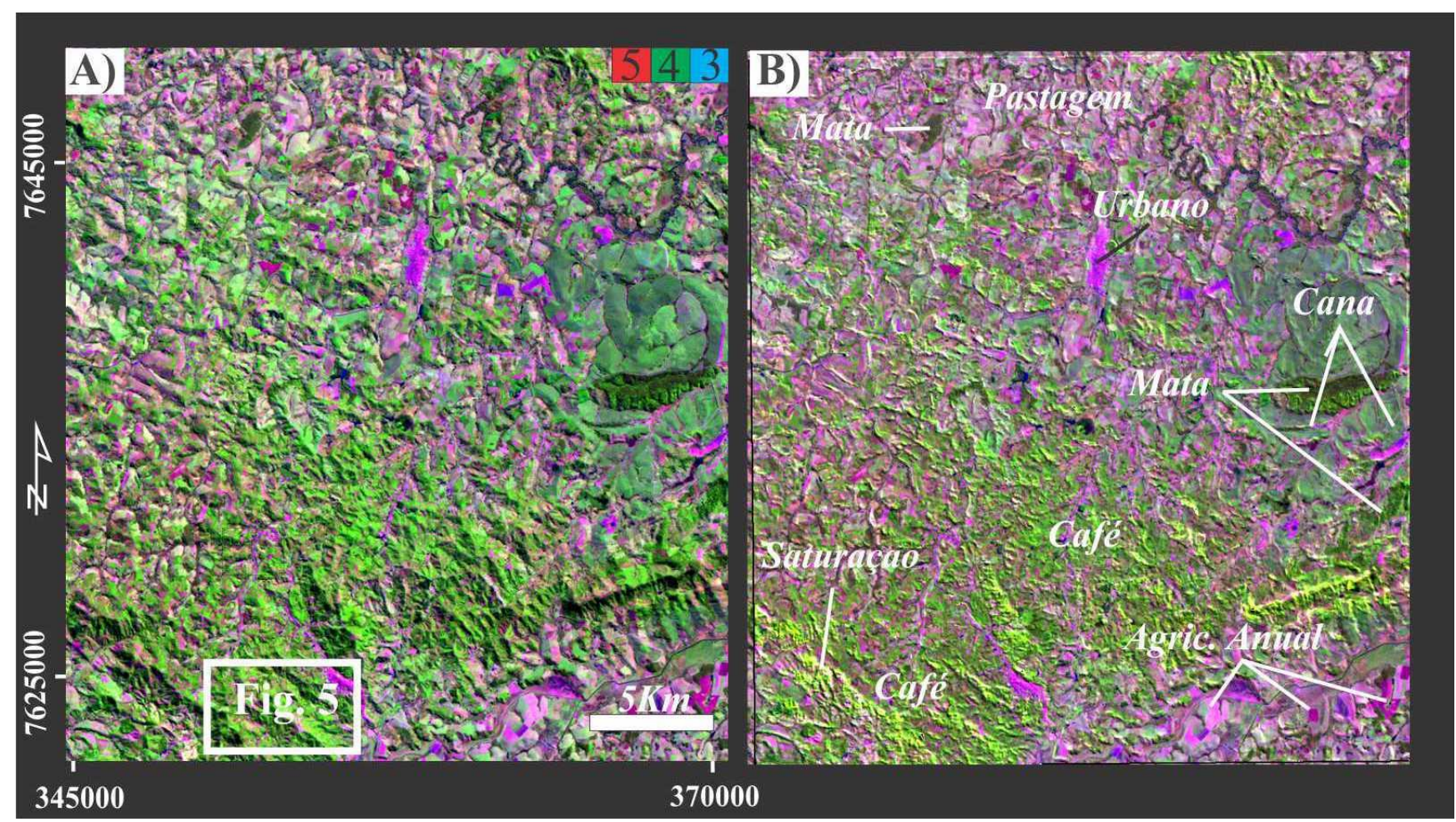

Figura 4: Comparação do efeito da correção topográfica utilizando a composição colorida bandas 543 em RGB do satélite Landsat-TM.

A classe Café Produção aparece na imagem com coloração verde escuro devido à alta refletância da vegetação no infravermelho próximo e o sombreamento projetado pelos pés de cafés nas linhas e entrelinhas do plantio. Nas áreas com declividades mais acentuadas, o Café Produção aparece na imagem com padrão semelhante às áreas de mata (DUARTE e BRITO, 2007). Soma-se ainda, ao fato de que algumas parcelas do Café Formação fazem fronteira com as áreas de mata, aumentando as confusões entre as classes. Nas lavouras que possuem maior presença de galhos secos, devido à idade mais avançada dos cultivares ou à prática de poda, observa-se certa semelhança espectral com as áreas de pasto seco em função da maior interação da energia eletromagnética com materiais não fotossinteticamente ativos.

A Tabela 1 ilustra de maneira detalhada os erros e acertos contidos na classificação gerada utilizando os procedimentos descritos. Conforme pode ser observado, a exatidão global foi de $58 \%$ e as médias da acurácia e da confiabilidade foram $52 \%$ e $60 \%$, respectivamente. A acurácia individual do Café Formação foi de $46 \%$ e a do Café Produção, ligeiramente inferior atingindo $41 \%$. Já a confiabilidade do Café Formação foi de apenas $8 \%$ e a do Café Produção, 60\%. As confusões mais comuns encontradas foram entre: Café Formação e Café Produção, resultantes da alta similaridade espectral dos cultivos e da saturação do efeito topográfico; Café Formação e Pastagem, pois como o café ainda encontra-se em formação, há uma forte interação da energia com o efeito de fundo, resultando em uma mistura com solo exposto, palha seca, ervas daninhas e folhas caídas nas entrelinhas do café; Café Produção e Mata, onde o cultivo é praticado em vertentes mais íngremes circundadas por áreas de mata de encosta

Ao comparar os resultados obtidos neste trabalho com a classificação convencional Maxver, utilizando as bandas 3, 4 e 5 do Landsat-5 TM sem correção topográfica, observou-se uma diferença expressiva da acurácia e da confiabilidade das classes Café Formação e Café Produção. Conforme pode ser observado na Tabela 2, as acurácias do Café Formação e Café Produção foram de $20 \%$ e $24 \%$, respectivamente. Ou seja, praticamente a metade da exatidão encontrada na primeira classificação. Já com relação à confiabilidade, as diferenças entre as duas classificações foram menores, porém ainda com vantagens ao utilizar a metodologia descrita. 

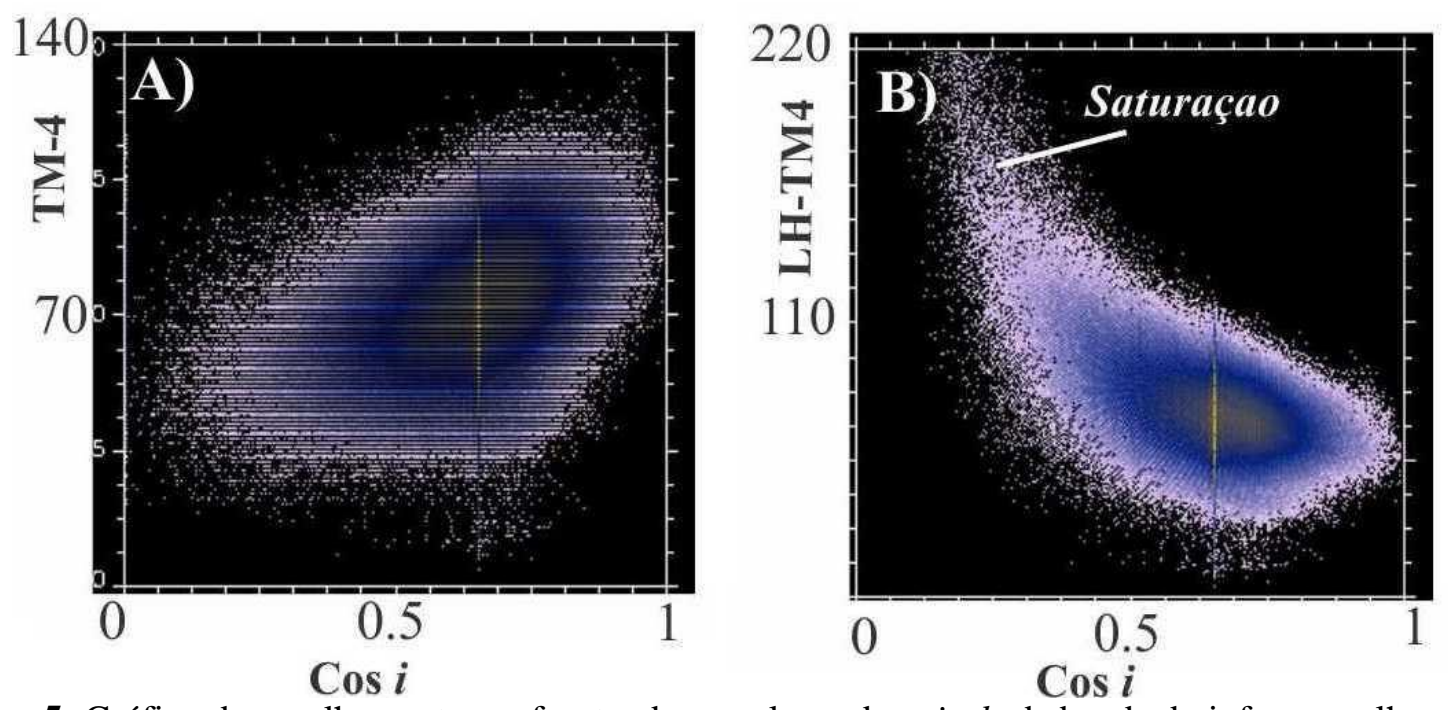

Figura 5: Gráfico de espalhamento confrontando os valores dos pixels da banda do infravermelho próximo (TM-4) com os valores do fator cosseno (Cos i) antes (A) e depois da correção topográfica (B).
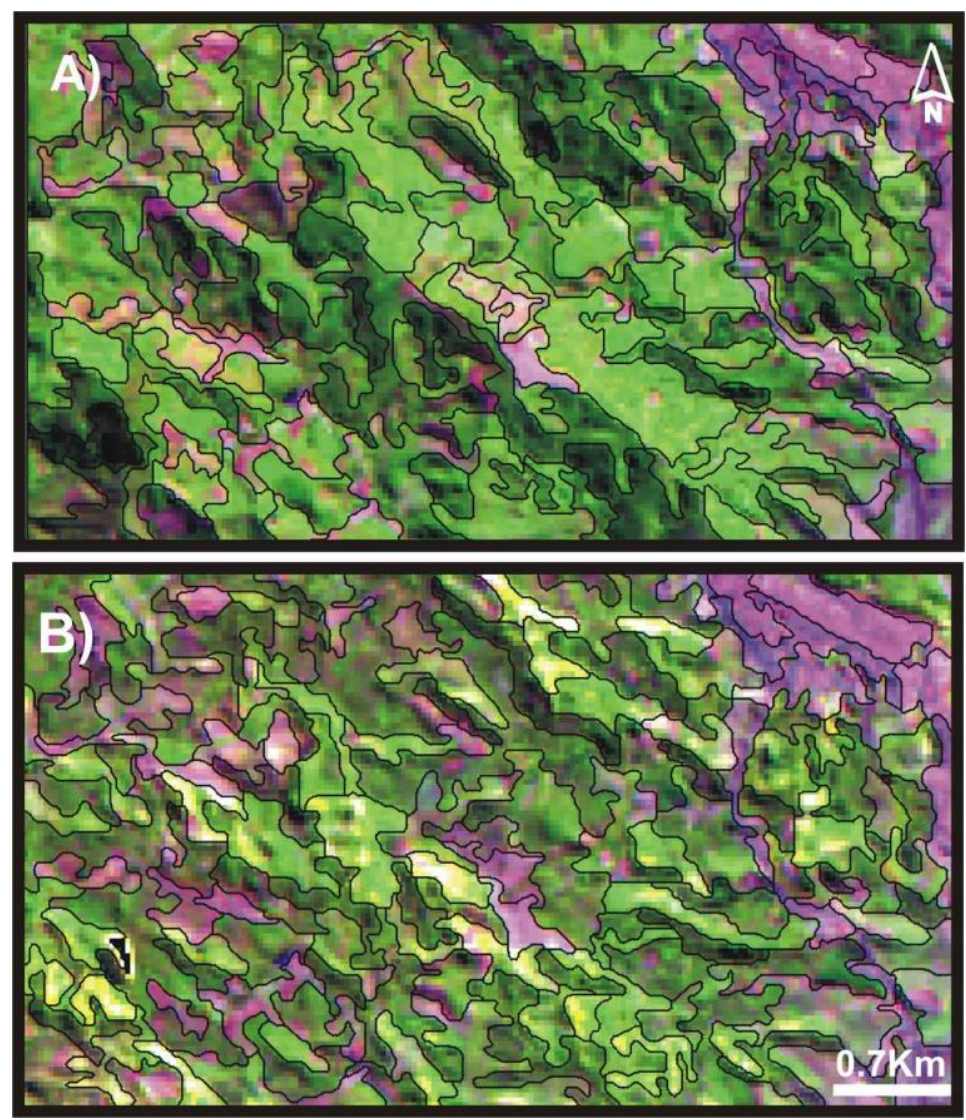

Figura 6: Detalhe do desempenho da segmentação sobreposta a composição colorida 5R4G3B antes (A) e após a correção topográfica (B).

Também é possível observar ao analisar a tabela que os erros encontrados na matriz de confusão da classificação Maxver foram ligeiramente mais dispersos, o que sugere maior heterogeneidade nas fontes de erros. Já com a metodologia empregada, os erros foram mais agrupados, o que demonstra, de certa forma, uma melhora no processo de classificação resultante da compensação das diferenças de iluminação, e por considerar atributos texturais na extração de informação.

A Figura 7 mostra o resultado do mapeamento do cultivo de café utilizando a metodologia descrita. Analisando-se a distribuição espacial do cultivo, é possível observar uma concentração do plantio especialmente do Café Produção na porção sul, dentro dos limites do município de Cabo 
Verde. Correlacionando o cultivo do café com as variáveis topográficas, observou-se que os plantios se concentram entre $800 \mathrm{~m}-1250 \mathrm{~m}$ de altitude, com predomínio na cota $1000 \mathrm{~m}$.

O café é plantado em terrenos com declividades bastante variadas, normalmente da meia vertente em direção aos topos, evitando-se os fundos de vales, com a finalidade de evitar os maiores riscos de ocorrências de geadas. A inclinação média das áreas cultivadas é de $21^{\circ}$ com máxima de $66^{\circ}$. Estes fatores ambientais (terrenos elevados e com alta inclinação) são importantes porque condicionam a produção de grãos de café de maior qualidade, e por consequência, de maior valor de mercado (BARBOSA et al., 2011). Por outro lado, a menor ocorrência de café na porção norte da área de estudo se deve as menores altitudes, maior susceptibilidade à eventos de geada, além da implementação do cultivo de cana-de-açúcar.

Vários trabalhos publicados na literatura especializada sugerem que o plantio de café seja praticado preferencialmente nas faces das vertentes voltadas para o norte, em razão da maior incidência de raios solares durante o ano (ALZUGARAY e ALZUGARAY, 1984; BARROS et al., 2007; CUSTÓDIO et al., 2010). Por outro lado, as vertentes voltadas para o sul, são menos aconselháveis, pois além de receber maior incidência de ventos frios no inverno, também recebem maior umidade, o que aumenta os riscos de doenças foliares como a ferrugem. Apesar destas restrições, no presente estudo, não foi constatado, pelo menos de maneira evidente, uma relação entre a disposição dos cultivos e a orientação das vertentes mais ou menos favoráveis ao desenvolvimento do cultivo. Este resultado sugere que outros fatores são mais determinantes para a escolha da área de plantio, como altitude, declividade, aspectos edafológicos e práticas de manejo.

\section{CONSIDERAÇÕES FINAIS}

O cultivo de café no sul de Minas Gerais apresenta grande diversidade espectral que é resultante de diversos fatores como manejo, idade, tamanho, espaçamento do cultivo, poda, influência do relevo etc. Em razão desta diversidade, o mapeamento utilizando técnicas de processamento digital de imagens não é uma tarefa trivial de ser executada, apresentando comumente erros elevados na classificação. O presente estudo, portanto, apresentou uma metodologia que faz uso de correção topográfica das imagens Landsat-5 TM e classificação por regiões com o objetivo de melhorar o desempenho do mapeamento da cultura do café em área de relevo montanhoso.

A técnica de redução da variação de iluminação da imagem por meio do fator cosseno mostrou-se útil para reduzir as variabilidades espectrais dos cultivos induzidos pela disposição do relevo. Todavia, observou-se um excesso de compensação de brilho (saturação) nas vertentes de maior inclinação voltadas para Sudoeste. Em razão da saturação, os resultados obtidos com a aplicação do método de correção topográfico pelo fator cosseno devem ser interpretados com cautela, pois a compensação excessiva de brilho também pode induzir a um aumento nos erros de confusão de classes.

A redução na variabilidade espectral do cultivo de café melhorou o desempenho da segmentação, criando regiões mais contínuas e representativas da forma do cultivo. A avaliação da classificação mostrou que apesar dos erros existentes ainda serem altos (adotando como referência padrão a exatidão de $75 \%$ ), os procedimentos adotados foram eficientes no mapeamento do cultivo do café, permitindo a separação de duas classes de café: o Café Formação e o Café Produção. Quando foi considerada na classificação apenas uma única classe de café, o desempenho melhorou consideravelmente. A exatidão global e as médias da exatidão e da confiabilidade subiram para $65 \%, 58 \%$ e $68 \%$, respectivamente.

Ao comparar os resultados da classificação obtida utilizando o método descrito no presente estudo com uma classificação convencional pixel a pixel pela máxima verossimilhança, observou-se que com o método adotado, houve uma redução na variabilidade dos erros. Por fim, os erros observados no mapeamento devem ser corrigidos manualmente para que os resultados possam ser utilizados de maneira mais eficiente no planejamento agrícola da região. 
Tabela 1: Matriz de confusão da gerada utilizando as imagens com correção topográfica e classificação por regiões

\begin{tabular}{|c|c|c|c|c|c|c|c|c|c|c|}
\hline $\begin{array}{l}\text { Classificação } \rightarrow \\
\text { Referência } \downarrow\end{array}$ & $\begin{array}{c}\text { Café } \\
\text { Formação }\end{array}$ & $\begin{array}{c}\text { Café } \\
\text { Produção }\end{array}$ & Mata & Pastagem & $\begin{array}{c}\text { Solo } \\
\text { Exposto }\end{array}$ & $\begin{array}{l}\text { Cultura } \\
\text { Temp. }\end{array}$ & Urbano & Água & Total & $\begin{array}{c}\text { Acurácia } \\
(\%)\end{array}$ \\
\hline Café Formação & 7 & 3 & 1 & 3 & - & 1 & - & - & 15 & 46,6 \\
\hline Café Produção & 45 & 46 & 13 & 5 & - & 3 & - & - & 112 & 41,0 \\
\hline Mata & 8 & 9 & 29 & 7 & 1 & 4 & - & - & 58 & 50 \\
\hline Pastagem & 15 & 16 & 8 & 113 & 2 & 13 & 3 & - & 170 & 66,4 \\
\hline Solo Exposto & 2 & - & 1 & 15 & 14 & - & 7 & - & 39 & 35,8 \\
\hline Cultura Temp. & 8 & 2 & 2 & 12 & - & 62 & - & - & 86 & 72,0 \\
\hline Urbano & - & - & - & 1 & - & - & 7 & - & 8 & 87,5 \\
\hline Água & - & - & 2 & 3 & - & - & 2 & 2 & 9 & 22,2 \\
\hline Total & 85 & 76 & 56 & 159 & 17 & 83 & 19 & 2 & 497 & \\
\hline Confiabilidade (\%) & 8,2 & 60,5 & 51,7 & 71,0 & 82,3 & 74,6 & 36,8 & 100,0 & & \\
\hline
\end{tabular}

Tabela 2: Matriz de confusão gerada utilizando as imagens sem correção topográfica e classificação Maxver.

\begin{tabular}{|c|c|c|c|c|c|c|c|c|c|c|}
\hline $\begin{array}{l}\text { Classificação } \rightarrow \\
\text { Referência } \downarrow\end{array}$ & $\begin{array}{c}\text { Café } \\
\text { Formação }\end{array}$ & $\begin{array}{c}\text { Café } \\
\text { Produção }\end{array}$ & Mata & Pastagem & $\begin{array}{c}\text { Solo } \\
\text { Exposto }\end{array}$ & $\begin{array}{l}\text { Cultura } \\
\text { Temp. }\end{array}$ & Urbano & Água & Total & $\begin{array}{c}\text { Acurácia } \\
(\%)\end{array}$ \\
\hline Café Formação & 3 & 1 & 4 & 3 & - & 4 & - & - & 15 & 20,0 \\
\hline Café Produção & 22 & 27 & 30 & 7 & - & 26 & - & - & 112 & 24,1 \\
\hline Mata & 1 & 4 & 38 & 1 & - & 13 & 1 & - & 58 & 65,5 \\
\hline Pastagem & 5 & 7 & 8 & 90 & 16 & 39 & 2 & 3 & 170 & 52,9 \\
\hline Solo Exposto & - & - & - & 2 & 20 & 8 & 9 & - & 39 & 51,2 \\
\hline Cultura Temp. & 2 & 20 & 5 & 13 & - & 44 & 1 & 1 & 86 & 51,1 \\
\hline Urbano & - & - & - & - & 3 & - & 5 & - & 8 & 62,5 \\
\hline Água & - & - & - & - & - & 1 & - & 8 & 9 & 88,8 \\
\hline Total & 33 & 59 & 85 & 116 & 39 & 135 & 18 & 12 & 497 & \\
\hline Confiabilidade (\%) & 9,0 & 45,7 & 44.7 & 77,5 & 51,2 & 32,5 & 27,7 & 66,6 & & \\
\hline
\end{tabular}




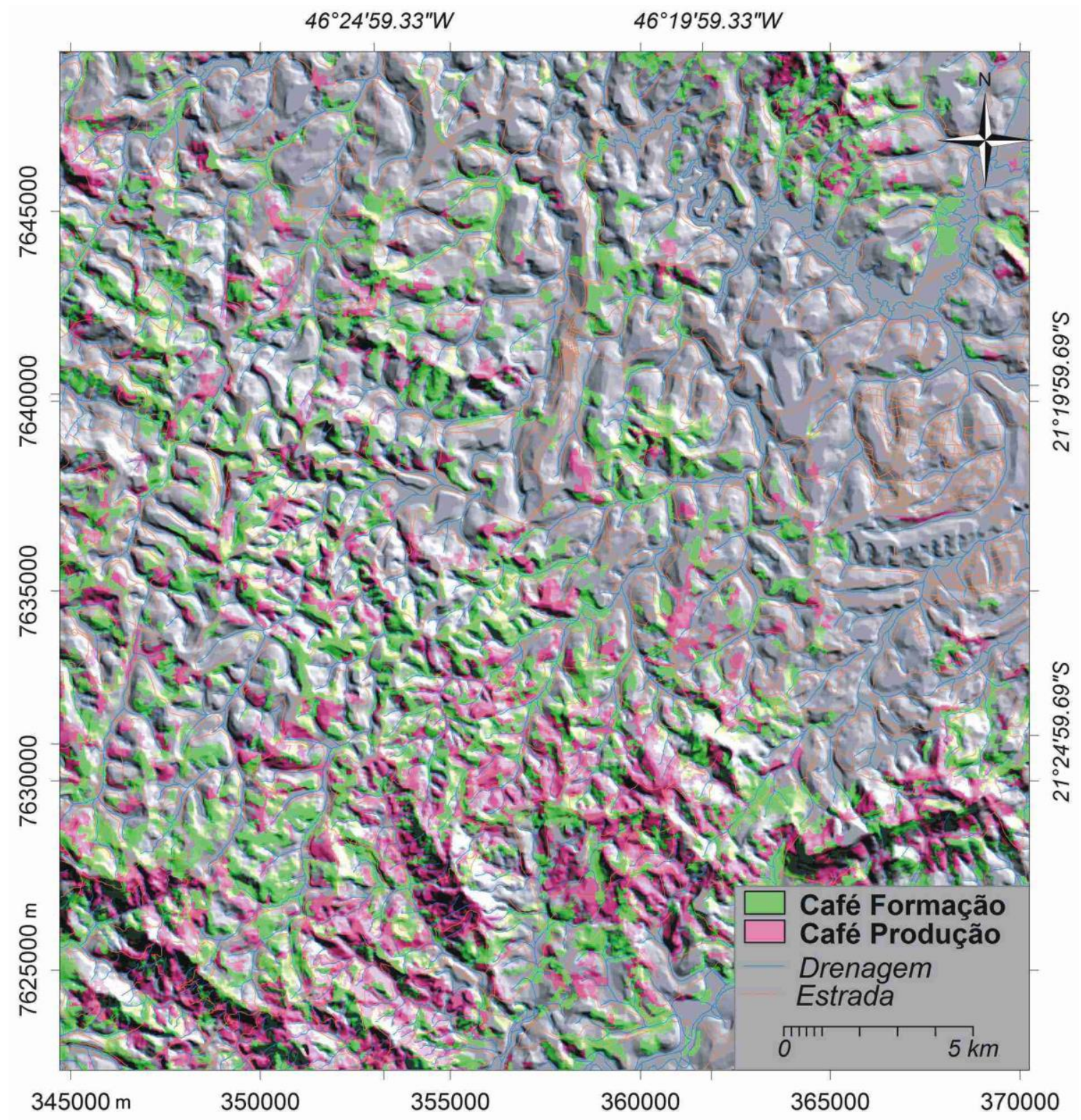

Figura 7: Resultado do mapeamento do cultivo de café utilizando as imagens submetidas à correção topográfica e classificação por regiões.

\section{AGRADECIMENTOS}

Os autores agradecem o auxílio financeiro concedido pela agência de fomento à pesquisa FAPEMIG e aos revisores da Revista do Departamento de Geografia (RDG) pelas valiosas sugestões.

\section{REFERÊNCIAS BIBLIOGRÁFICAS}

ALLEN, T. R. Topographic Normalization of Landsat Thematic Mapper Data in Three Mountain Environments. Geocarto International, v. 15, n. 2, p. 15-22, 2000.

ALVES, D. S.; MOREIRA, J. C.; KALIL, E. M.; SOARES, J. V.; FERNANDEZ, O.; ALMEIDA, S.; ORTIZ, J. D.; AMARAL, S. Mapeamento do Uso da Terra em Rondônia Utilizando Técnicas de Segmentação e Classificação de Imagens TM. VIII Simpósio Brasileiro de Sensoriamento Remoto. Anais... Salvador: Instituto Nacional de Pesquisas Espaciais, 1996.

ALZUGARAY, D.; ALZUGARAY, C. Flora brasileira. São Paulo: Três Livros, 1984.

BARBOSA, J. N.; RIBEIRO, D. E.; TAVEIRA, J. H. S.; ZANELLA, L.; BORÉM, F. M.; ISQUIERDO, E. P.; COLPA, S. R. C.; CARVALHO, L. A.A expressão da qualidade do café natural produzido em diferentes 
ambientes da microregião da Serra da Mantiqueira. VIII Simpósio de Pesquisas dos Cafés do Brasil. Anais... Araxá: 2011

BARROS, M. A.; MOREIRA, M. A.; RUDORFF, B. F. T. Dados interferométricos para modelagem topográfica e caracterização ambiental do café em escala municipal. Sociedade \& Natureza (Online), v. 19, n. 2, p. 33-50, dez. 2007.

BERNARDES, T; MOREIRA, M. A.; ADAMI, M.; GIAROLLA, A.; RUDORFF, B. F. T. Monitoring biennial bearing effect on coffee yield using MODIS remote sensing imagery. Remote Sensing, n. 4, p. 2492-2509, 2012.

BINS, L. S. FONSECA, L. M. G.;ERTHAL, G. J.; II, F. M. Satellite Imagery Segmentation : a region growing approach. III Simposia Brasilerio de Sensoriamenta Remoto, Anais... Salvador: Instituto Nacional de Pesquisas Espaciais, 1996.

CÂMARA, G.; SOUZA, R. C. M.; FREITAS, U. M.; GARRIDO, J. Spring: Integrating remote sensing and gis by object-oriented data modelling. Computers and Graphics, v. 20, n. 3, p. 395-403, 1996.

CERON, A. O.; DINIZ, J. A. F. O Uso das fotografias aéreas na identificação das formas de utilização agrícola da terra. Revista Brasileira de Geografia, v. 2, p. 161-173, 1966.

CONAB. Safra de café 2010. Disponível em: <www.conab.gov.br/conteudos>.

CORDERO-SANCHO, S.; SADER, S. A. Spectral analysis and classification accuracy of coffee crops using Landsat and a topographic-environmental model. International Journal of Remote Sensing, 5 abr. 2007.

CRÓSTA, A. P. Processamento digital de imagens de sensoriamento remoto. Campinas: Unicamp, 1992.

CUSTÓDIO, A. A. P.; POZZA, E. A.; CUSTÓDIO, A. A. P.; SOUZA, P. E.; LIMA, L. A. L.; LIMA, L. M.Intensidade da ferrugem e da cercosporiose em cafeeiro quanto à face de exposição das plantas. Coffee Science, v. 3, p. 214-228, 2010.

DUARTE, W. DE O.; BRITO, J. L. S. Mapeamento da cultura do café no município de ARAGUARIMG utilizando imagens do Sensor CCD do satélite CBERS-2. XIII Simpósio Brasileiro de Sensoriamento Remoto. Anais... Florianópolis: Instituto Nacional de Pesquisas Espaciais, 2007

EKSTRAND, S. Landsat TM-Based Forest Damage Assessment: Correction for Topographic Effects. Photogrammetric Engineering \& Remote Sensing, v. 62, n. 2, p. 151-161, 1996.

EPIPHANIO, J. C. N.; LEONARDI, L.; FORMAGGIO, A. R. Relação entre parâmetros culturais e resposta espectral de cafezais. Pesquisa Agropecuária Brasileira, v. 29, n. 3, p. 439-447, 1994.

FILETTO, F.; ALENCAR, E. Organizações Rurais e Agroindustriais. Organizações Rurais e Agroindustriais, v. 3, n. 1, 2001.

GORTE, B. G. H.; KOOLHOVEN, K. Interpolation between isolines based on the Borgefors distance transform. ITC Journal, v. 3, p. 245-247, 1990.

HARALICK, R. M.; SHAPIRO, L. G. Image segmentation techniques. Computer Vision Graphics and Image Processing, v. 29, n. 1, p. 100-132, 1985.

JENSEN, J. R. Introductory digital image processing: a remote sensing perspective. Second edition. Upper Saddle River: Prentice Hall, 2005.

KAWAKUBO, F. S.; MORATO, R. G.; MIDAGLIA, C. L.; GOMIDE, M. L.C.; LUCHIARI, A.Land-use and vegetation-cover mapping of an indigenous land area in the state of Mato Grosso (Brazil) based on spectral linear mixing model, segmentation and region classification. Geocarto International, v. 24, n. 2 , p. 165-175, 2009.

KAWAKUBO, F. S.; MORATO, R. G.; LUCHIARI, A. Use of fraction imagery, segmentation and masking techniques to classify land-use and land-cover types in the Brazilian Amazon. International Journal of Remote Sensing, v. 34, n. 15, p. 5452-5467, 2013.

LEÃO, C.; KRUG, L.A.; KAMPEL, M.; FONSECA, L .M. G. Avaliação de métodos de classificação em imagens TM/Landsat e CCD/CBERS para o mapeamento do uso e cobertura da terra na região costeira do extremo sul da Bahia. XIII Simpósio Brasileiro de Sensoriamento Remoto. Anais... Florianópolis: Instituto Nacional de Pesquisas Espaciais, 2007 
LIMA, H. C.; DORANTI, C.; HACHSPACHER, P. C.; RIBEIRO, M. C. S.; RIBEIRO, L.F. B. Morphometric analisys of Machado Drainage Basin - Minas Gerais State. Sociedade \& Natureza, v. 22, n. 1, p. 23-34, 2010.

MOREIRA, E. P.; VALERIANO, M. M.; SANCHES, I. D. A.; FORMAGGIO, A. R. Efeito topográfico sobre dados TM/Landsat e impactos sobre índices de vegetação. XVII Simpósio Brasileiro de Sensoriamento Remoto. Anais... João Pessoa: Instituto Nacional de Pesquisas Espaciais, 2015

MOREIRA, M. A.; BARROS, M. A.; FARIA, V. G. C.; ADAMI, M. Tecnologia de informação: imagens de satélite para o mapeamento de áreas de café de Minas Gerais. Informe Agropecuário, v. 28, p. 27-37, 2007.

MOREIRA, M. A.; RUDORFF, B. F. T.; BARROS, M. A.; FARIA, V. G. C.; ADAMI, M. Geotecnologias para mapear lavouras de café nos estados de Minas Gerais e São Paulo. Engenharia Agrícola, v. 30, n. 6, p. 1123-1135, dez. 2010.

MOREIRA, M. A.; ADAMI, M.; RURDORFF, B. F. T. Spectral and temporal behavior analysis of coffee crop in Landsat images Abstract. Pesquisa Agropecuária Brasileira, v. 39, n. 3, p. 223-231, 2004.

MOREIRA, M. A.; BARROS, M. A.; RUDORFF, B. F. T. Geotecnologias No Mapeamento Da Cultura Do Café Em Escala Municipal. Sociedade \& Natureza, v. 20, n. 1, p. 101-110, 2008.

RADAMBRASIL. Mapa de Vegetação da Folha Rio de Janeiro/Vitória SF.23/24. Rio de Janeiro: Ministério das Minas e Energia, 1983.

RAMIREZ, G. M.; ZULLO JÚNIOR, J. Estimativa de parâmetros biofísicos de plantios de café a partir de imagens orbitais de alta resolução espacial. Engenharia Agrícola, v. 30, n. 3, p. 468-479, jun. 2010.

RIAÑO, D.; CHUVIECO, E.; SALAS, J.; AGUADO, I. Assessment of different topographic corrections in Landsat-TM data for mapping vegetation types (2003). Geoscience and Remote Sensing, IEEE Transactions on, v. 41, n. 5, p. 1056-1061, 2003.

SHEPHERD, J. D.; DYMOND, J. R. Correcting satellite imagery for the variance of reflectance and illumination with topography. International Journal of Remote Sensing, v. 24, n. 17, p. 3503-3514, 2003.

TARDIN, A. T.; ASSUNÇÃO, G. V.; SOARES, J. V. Análise preliminar de imagens TM visando a discriminação de café, citrus e cana-de-açúcar na região de Furnas-MG. Pesquisa Agropecuária Brasileira, v. 27, p. 1355-1361, 1992.

VIEIRA, T. G. C.; ALVES, H. M. R.; BERTOLDO, M. A.; SOUZA, V. C. O. Geotecnologies in the assessment of land use changes in coffee Regions of the state of Minas Gerais in Brazil. Coffee Science, v. 2, p. 142-149, 2007. 